\title{
Working Capital Management Programs: Yesterday, Today, Tomorrow
}

\author{
Wim Westerman \\ University of Groningen, Groningen, the Netherlands
}

\begin{abstract}
The paper develops a view on the history and future of working capital programs and focuses on the state of the art in four remarkable years: 1900, 1930, 1960, and 1990. In these years, an operations approach, an accounting approach, an economic approach, and a capital market approach, respectively, were prevalent. The paper shows that all of the approaches have their merits for today's working capital management (WCM) programs and discusses useful working capital program indicators, taking into account the cash conversion cycle (CCC) and its delineation into accounts receivables $(\mathrm{A} / \mathrm{R})$, inventory, and accounts payables $(\mathrm{A} / \mathrm{P})$ periods. This enables the author to take step ahead to the magic year 2020. Finally, the paper discusses briefly an academic development agenda.
\end{abstract}

Keywords: working capital programs, working capital approaches, program indicators, academic agenda

\section{Introduction}

Working capital management (WCM), referring to accounts receivable (A/R), inventory, and accounts payable (A/P) issues, is gaining attention nowadays. Firms start programs to handle working capital better and cheaper. However, programs that are skewed towards making fast gains are difficult to sustain. Also, much digging beyond obvious financial numbers is required. The author's point is that the orientation of the programs can improve by drawing lessons from the past and taking current challenges into account. Firms can take a step ahead with a real-time information approach that deals with supply chain issues quantitatively and qualitatively.

This paper starts with a view on the history of WCM. The author does this in a condensed way, focusing on the state of the art in four remarkable years: 1900, 1930, 1960, and 1990. In doing so, lessons for today's WCM can be drawn. This helps the author to develop a view on current WCM programs. Looking behind these programs, useful indicators can be discerned. This leads to a discussion of how specific indicators can be used in future working capital programs ("2020”). This paper concludes with some remarks on the academic development agenda. Table 1 visualizes the WCM programs view that is depicted in this article.

Table 1

Working Capital Program Development Over Time

\begin{tabular}{|l|l|l|}
\hline Date and label & Key term & Lesson for WCM programs \\
\hline 1900: Operations approach & Stocks/flows, cash cycle & Define tasks, plan and control \\
\hline 1930: Accounting approach & Reporting, ratios, norms & Provide early warning signals \\
\hline 1960: Economic approach & Formulas, net present value & Make economic calculations \\
\hline 1990: Capital markets approach & Cash flows, outsourcing & Identify specific WCM drivers \\
\hline 2020: Information approach & Systems, indicators, narratives & Real-time supply chain control \\
\hline
\end{tabular}

Wim Westerman, doctor, Faculty of Economics and Business, University of Groningen. Email: w.westerman@rug.nl. 


\section{Operations Approach (1900)}

The sovereign state concept was refined at the turn of the 19th into the 20th century. The globe aligned itself into states and colonies. Sovereign state borders were established and/or became protected. Government bureaucracies were brought to perfection. Ever larger firms sought for ways to structure their clouds of operations. The Taylorian concept of scientific management showed how specialization led to both the division of operational tasks and a need for corporate alignment of the activities.

WCM became a matter of governing short-term stocks and flows. Purchase orders, creditors, equipment and materials, work in progress, finished products, debtors, and cash were labeled as such. The (operational) working capital cycle and its twin (financial) cash cycle concepts helped to control working capital both overall and specific. Working capital levels were important, as individual items had to be available if (because of regulations) and when (because of activities) needed. Corresponding costs were sensed as being a fact of life. After all, interest rate levels were low.

Today, it is felt that one can have more grip on working capital when financial staff dig more into the operations of their firms. Vice versa, operational staff may deepen their grasping of financial issues of working capital. For too long, A/R management was exclusively a financial domain and inventory management was done by operations, for example. Joint efforts may lead towards more streamlining. Also, the working capital function may want to look at its own operations, e.g., by aligning planning and control, as well as defining tasks to be centralized or decentralized.

\section{Accounting Approach (1930)}

When assuming more and more tasks trying to handle economic crises, many governments started to introduce taxes on sales, margins, and profits. Accountants developed rules for reasonably unified reporting schemes that helped the governments to levy taxes meaningfully. Bookkeeping advanced in such a way that the data provided became evermore reliable. It also became accepted that working capital stocks ("balances”) and flows could be managed with the help of accounting systems.

Accounting systems deliver various performance data. From now on, problems on judging corporate performance were solved by breaking down, in terms of the Du Pont chart, the net profit measure into various ratios, including those on short-term assets and debts. Calculation of ratios that referred to working capital items could improve the WCM of the firm. Not only working capital to sales and working capital to assets, current ratio (CR), and quick ratio (QR), but also various individual asset turnover and capital intensity ratios came to the fore. All kinds of norms (hunches) were developed for individual items. Still, working capital costs, although rising, were thought to be largely inevitable.

Ratio management seems to have become part of daily life in WCM. With today's in many aspects real-time management accounting and finance systems, the jurisdiction for applying ratios has grown. Especially, easy-to-calculate early warning ratios, e.g., days of sales outstanding, or even plain indicators such as bank account levels, help to signal problems when they arise. With corporate risk management evolving as a discipline, sensitivity and scenario analyses on working capital ratios may receive more priority.

\section{Economic Approach (1960)}

With governments leaving more and more tasks to financial markets, financial economics as a discipline especially developed in the 1950s and 1960s. WCM could be done properly by applying economic formulas. 
The well-known inventory management formula of Camp (20's) was refined by Baumol (50's) and Miller/Orr (60's). Whereas rules of thumb remained popular for use in business, the formulas were applied evermore by enthusiastic academics.

It was believed that sophisticated (linear) programming would allow for solving all kinds of stock and flow problems within reasonable boundaries. The computer was being refined such that applications of the economic formulas indeed became feasible, but their use remained limited. With rising interest rates, working capital costs became an issue. Inventory, debit, and credit terms were being framed in net present value calculations. However, at the same time, costs became more under control as well. General economic conditions and corporate sales forecasts flew into working capital (item) budgets and actual working capital performance was evaluated subsequently.

As of today, it seems that the formulas meant above are not much applied, albeit that they are readily calculated with major software packages. Economic calculations are typically made case-wise, when trading off various alternatives. As it seems that these alternatives become feasible in ever shorter timeframes, the application of the formulas in corporate practice may rise. If so, the management control of working capital items at hand becomes more useful, albeit with less focus on inflexible budgets and performance evaluations, but with more pressure of clear working capital programs.

\section{Capital Markets Approach (1990)}

Around 1990, financial markets were liberalized, deregulated, and harmonized rapidly. The 1987 stock market crash had just caused temporary problems, the Berlin Wall protecting communism had just fallen, and financial economics as a discipline was developing fast. Moreover, evermore simplified information systems became widely available. No wonder that notions of global market perfection and market efficiency came on the top of minds, affecting the financial management field tremendously.

WCM became to be judged to be a contemporary issue, to be solved over time with evermore perfect short-term financial markets developing. With worldwide falling financial costs of (working) capital balances in a general economic upswing, well-functioning financial markets lowered these even further. Yet, as a result, the focus went to working capital cash flows. Windfall savings and programmed savings, both on stocks and flow items, became remarkable since. With working capital not being a core issue anymore, firms started to outsource the management thereof.

However, firms learnt that control of operational corporate cash flows was still very much important. When deeply understanding cash flows, including the individual drivers of the parts thereof, WCM may improve. Moreover, with capital availability and capital costs being on the top of minds in the course of the financial crisis, there is room for a renewed strive for improving WCM. For example, sophisticated forecasting of working capitals can help to control financial needs better and value-based working capital scans may induce learning effects.

\section{Today’s Working Capital Programs}

In the course of the financial crisis, banks curtailed loan balances, raised their interest spreads, and introduced more bureaucracy (Westerman, 2010). Firms found out that it is not business as usual anymore. They must make better business plans, control cash flows more strictly, and improve their reports. They have to raise the precautionary working capital balances. Also, they must grasp both financial markets and their own operations better, and strive for better alignment between the two. 
After a long period of relative stability, working capital items have apparently been falling recently (REL, 2014). However, during crisis times, many firms cut inventories, manage A/P more strictly, and lower idle $\mathrm{A} / \mathrm{R}$ balances. They also optimize the supply chain, e.g., curtailing risks on supplier and buyer counterparties. In doing so, they think in terms of “quick win” working capital programs. Structural programs that continue the incidental measures are difficult to establish, but examples with a growing number of firms are much promising.

Value-creating working capital programs can be grounded in the cash and operating cycle of the firm ("cash conversion cycle" (CCC)), for example, conceptualized and measured as a "cash (flow) wheel". The speed of turning on the wheel is determined by the firm's effectiveness and efficiency in terms of managing separate and shared working capital items of diverse units at multiple levels. Performance planning and control of working capital requires "real-time" attention and effort.

\section{Valuing Working Capital Programs}

Calculating the value of working capital programs is not that easy. The effects are often difficult to point out and uncertain. In case an empirical basis for making estimations is lacking, basic hunches may be applied. While this is well understandable for practical use, improvements are possible. Especially, firms may want to evade the following common biases that may show up in practice when working capital program benefits are estimated (cf. Fernandez, 2003; Westerman, 2010).

\section{Cost Bias}

Cost savings from working capital programs are readily to be calculated in terms of man hours, warehouse costs, and interest reduction. However, when cutting low hanging fruit of previously less controlled costs, revenues may be hurt. For example, if cutting A/R by tightening credit terms, customers may walk away, competitors may take over, etc.. These opportunity losses should be taken into account upfront, such as sales managers may be keen to point out.

\section{Profit Bias}

Cash is often proclaimed to be king, but profit may still rule. Yet, even with a profit focus, working capital program assessments should be correct. For example, inventory depreciation and credit depreciation issues have to be considered. Also, using a factoring scheme will not only save full-time equivalent, but also induce charges by the factoring firm. However, the cash is received earlier than before, which lowers the financing need. Moreover, a profit approach leaves the time factor out of the calculations.

\section{Operations Bias}

If cash is king, it counts for all. Not just operational cash flows, but also investment cash flows determine the free cash flow. As an example, when speeding up collection periods, the resultant cash balances may require sophisticated investment management. Calculations also have to account for changeover costs of accompanying systems, whether depreciable in one year or not. Also, although it is quite tempting to treat them as sunk costs, consultancy fees are also upfront investments.

\section{Short-Term Bias}

Long-term effects of measures may differ from short-term effects, e.g., quick inventory cuts may do well in hard times. However, strict just-in-time inventory management may imply missing upward trends. Also, with high real interest rates, chasing customers may be justifiable. However, in a generally softer credit cycle, such 
aggressiveness may not be effective or efficient. Lastly, consequences of paying suppliers late, in the current low cost (interest) environment, may materialize in losing a supplier as a partner forever.

\section{Interest Bias}

Economically, long-term free cash flows must be discounted because of time preference and risk effects. However, this necessitates the application of a cost of capital that reflects all financing costs. The market-wide interest rate provides a basic hunch, but the weighted average cost of capital (WACC) is in principle the correct factor. Working capital can in general not be separated from the rest of the operations and so a rate that accounts for the general economic vulnerability must be used.

\section{Working Capital Program Indicators}

Working capital programs refer to $\mathrm{A} / \mathrm{R}$, inventory (accounts), and $\mathrm{A} / \mathrm{P}$. The programs aim to limit net investments in these accounts, taking into account costs and risk involved. Working capital (parts) programs can be related to assets and consequently also to sales. A basis performance indicator of working capital is the CR, current assets divided by current liabilities; the QR leaves out the inventory from the current assets.

Working capital patterns differ per country and industry (cf. Dorsman \& Gounopoulos, 2008). Preve and Sarria-Allende (2010) mentioned four macro-economic factors: monetary constraints, interest rates, inflation, and crisis, which together may cause financial distress at the firm level. Preliminary research of the present author indicates moreover that leverage is indeed a determining factor. Preve and Sarria-Allende (2010) held that the four drivers of working capital are sales, prices, growth, and seasonality.

A/R depends upon sales volume, sales price, and days of credit to customers (Preve \& Sarria-Allende, 2010). A/P relates to purchase volume, purchase price, and days of credit from suppliers. Inventory is related to sales volume, cost of goods sold, and days in inventory. The Days of Sales Outstanding (DSO), Days of Inventory Outstanding (DIO), and Days of Payment Outstanding (DPO) constitute the length of the operating cycle or CCC.

The DSO equals the A/R at the end of period divided by the average daily sales, the DPO equals the A/P at the end of period divided by the average daily cost of goods sold (or sales, which is less theoretically sound), the DIO equals the inventory at the end of period divided by the average daily cost of goods sold, and the CCC is equal to DSO - DPO + DIO. The CCC is also at times defined as the net non-monetary working capital divided by the average daily sales. Next to CCC, DSO, DPO, and DIO, also the inverses thereof are used to calculate turnover ratios.

The DSO can be broken down to arrive at schedules that show aging as fraction of receivables. The DSO can be compared to the Best Possible Days of Sales Outstanding (BPDSO) (Olsen, 1999): the weighted average of the payment terms. The spread between the DSO and the BPDSO is the average days in delinquency (ADD). The Collection Effectiveness Index (CEI) measures the effectiveness of the collection process (Olsen, 1999). It equals the quotient of beginning receivables plus monthly sales minus total period receivables and beginning receivables plus monthly sales minus current period receivables. Still, other indices are the Receivables (Outstanding) to Original Sales (ROOS) and the proportion of payments collected versus the sales of the origination months (PP). Finally, the Sales Weighted Days of Sales Outstanding (SWDSO) is the sum of the DSO per original sales month. 
The inventory turnover (turns) is the cost of goods sold over a period divided by the average inventory over this period. The DIO can be broken down into Days in Raw Material (DRM), Days of Work in Progress (DWIP), and Days in Fished Goods (DFG). The DIO can be split up into schedules that show aging as fraction of payables. The Inventory Quality Ratio (IQR) is the quotient of the active (moving) inventory and the total inventory. Forecast accuracy is the sum of the deviation of inventory forecast versus the actual inventory demand per period. Customer service can be measured as the quotient of the number of times an item is provided and the number of times that it has been demanded (Sherr, 1989).

As with the DSO, the DPO can be broken down with schedules showing aging as fraction of payables. Next to the DPO, the Best Possible Days of Payable Outstanding (BPDPO) can be constructed as the weighted average of the receivables terms. The Average Days Over Terms (ADT) measures the efficiency of the payments department as the spread between the DPO and the BPDPO.

\section{Information Approach (“2020”)}

In the nearby future, e.g., when looking ahead to the magic year 2020, working capital programs should be embedded in the corporate short- and long-term information management. Such an approach requires a systematic measuring of indicators that provide real-time signals of out-of-line situations. These signals may be augmented by narratives that go beyond economic conditions excuses and discuss supply chain control issues, e.g., loss of customers, machine breakdowns, and supplier disputes.

Table 2 provides an overview of the indicators that can be used for running WCM programs. Two levels of operations are discerned, namely, the holding level and the business unit level. A soft distinction is made between structural indicators that call for in-depth action and warning indicators that signal potential issues. More general and therefore rather exogenously given variables are separated from the rather endogenous operational and financial variables that can be influenced.

Several initiatives already show how near future WCM programs will look like. For example, intra-industry payment systems arise. The same goes for regional and local payment system initiatives in both developed and developing countries. Bank functions for transactions are partly insourced this way. Whereas this disintermediation wave is of course partly induced by the financial crisis, it also has its own merits in that costs and risks can be shared and thereby lowered.

Table 2

Working Capital Program Indicators and Their Usefulness

\begin{tabular}{|l|l|l|}
\hline Firm level & Structural indicator & Warning indicator \\
\hline Headquarters & $\begin{array}{l}\text { General: Working capital-to-assets/sales, } \\
\text { CR, QR, CCC } \\
\text { Specific: DSO, DIO, DPO }\end{array}$ & $\begin{array}{l}\text { General: Monetary constraints, interest rates, } \\
\text { inflation, crisis } \\
\text { Operations: Assets, net income, sales (growth), } \\
\text { operating margin } \\
\text { Financing: Cash, leverage }\end{array}$ \\
\hline \multirow{3}{*}{ Business unit } & $\begin{array}{l}\text { A/R: SWDSO, aging of sales, } \\
\text { ADD (= DSO - BPDSO), CEI, } \\
\text { ROOS, PP } \\
\text { Inventory: Aging of inventory, } \\
\text { DRM/DWIP/DFG, IQR, forecast accuracy, } \\
\text { customer service } \\
\text { A/P: Aging of payables, ADT (= DPO - BPDPO) }\end{array}$ & $\begin{array}{l}\text { General: DSO, DIO, DPO } \\
\text { Operations: Man hours, warehouse costs, } \\
\text { interest costs, investments }\end{array}$ \\
\hline
\end{tabular}




\section{An Academic Step Ahead}

WCM does not equal to cash management, but academic studies give another impression. Many study corporate cash holdings (Opler, Pinkowitz, Stulz, \& Williamson, 1999; Von Eije, 2012). This gives much insight into the amount and drivers of cash, such as firm size, growth, and liquidity. These already well-known factors do matter in the other working capital areas and so it might be wise to continue on that track. Governance, organization, culture, information, and behavioral concepts may further the understanding with trend breaks and at the firm level (Polak, Robertson, \& Lind, 2011).

Academic discussions generally lack in precision and integration and fail to respond to practitioners' needs (cf. Viskari, Lukkari, \& Kärri, 2011). Yet, several new books on WCM programs have been published recently (Preve \& Sarria-Allende, 2010; Platt, 2010; Sagner, 2014). All employed an eclectic approach, but with varying accents on operational, accounting, economic, and capital markets issues. Interesting are the additions on general economics, cash, and debt (Preve \& Sarria-Allende, 2010), strategy and corporate value (Platt, 2010), as well as banks, risk, liquidity, and information (Sagner, 2014).

The recent books set a step ahead in that they go beyond incorporating past approaches on WCM. Still lacking is a more in-depth information-driven supply chain approach though. Today's firms are able to process large amounts of data and early warning systems can flash signals when things go wrong. This also enables the working capital staff to go beyond the indicators and to suggest specific measures in the A/R, inventory, and $\mathrm{A} / \mathrm{P}$ area, be it with partners either inside or outside the firm.

\section{Summary and Conclusions}

Ever more firms are developing eclectic working capital systems, using an array of warning and structural indicators that can handle short- and long-term programs. Also, the academic world sets steps ahead by amalgamating operations, accounting, economic and capital market approaches into a coherent framework. Both can, however, do more on taking the CCC into account and having its parts to be specifically and jointly studied and handled swiftly by measures that create value in the firm's supply chain.

In the above, readers may find a reinforcement of efforts towards finding appropriate measures on $\mathrm{A} / \mathrm{R}$, inventory, and A/P balances and flows from external economics and corporate (unit) perspectives. Having noted this, the purpose of this paper can best be understood as a plea for taking small steps towards aligning operational and financial information on quantitative and qualitative issues of working capital programs as a business field worthy of more practical and scholarly effort.

\section{References}

Dorsman, A., \& Gounopoulos, D. (2008). Controlling working capital in multinational enterprises. Journal of Corporate Treasury Management, 2(2), 152-159.

Fernandez, P. (2003). Company valuation methods: The most common errors in valuations. ICFAI Journal of Accounting Research, 2(3), 31-56.

Olsen, R. (1999). Performance measures for credit, collections, and accounts receivable. Credit Research Foundation. Retrieved from http://www.crfonline.org/orc/ca/ca-7.html

Opler, T. L., Pinkowitz, L., Stulz, R., \& Williamson, R. (1999). The determinants and implications of corporate cash holdings. Journal of Financial Economics, 52(1), 3-46.

Platt, H. (2010). Lead with cash: Cash flow for corporate renewal. London: Imperial College Press.

Polak, P., Robertson, D. C., \& Lind, M. (2011). The new role of the corporate treasurer: Emerging trends in response to the financial crisis. International Research Journal of Finance and Economics, 78, 48-69. 
Preve, L., \& Sarria-Allende, V. (2010). Working capital management. Oxford: Oxford University Press.

REL. (2014). 2013 Europe working capital survey. The Hackett Group. Retrieved from http://www.relconsultancy.com/research/2013/relwcsurvey-eu/REL2013-Europe-Working-Capital-Survey.pdf

Sagner, J. S. (2014). Working capital management: Applications and cases. Hoboken, NJ: John Wiley \& Sons.

Sherr, F. C. (1989). Modern working capital management. Englewood Cliffs, NJ: Prentice Hall.

Viskari, S., Lukkari, E., \& Kärri, T. (2011). State of working capital management research: Bibliometric study. Middle Eastern Finance and Economics, 14, 99-108.

Von Eije, J. H. (2012). What causes differences in cash holdings between listed and unlisted firms around the world? Retrieved from http://papers.ssrn.com/sol3/papers.cfm?abstract_id=2010053

Westerman, W. (2010). The value of working capital programs in the credit crunch. Journal of Corporate Treasury Management, 3(3), 249-254. 